been tried, and some can be tolcrated. A product of this group known as sinthalin is now on the market. It is doubtful whether it can be administered in sufficient dases to control the blood sugar, but there is no doubt that the drug does give rise to considerable gastritis and some diarrhoea. This is likely to control the amount of food ingested, and by so doing will materially improve the middle-aged diabetic, who eats and drinks too much.

\section{PULMONARY FIBROSIS :}

An Investigation into the Obigin and Cockse. BY

C. ve W. KITCAT, M.R.C.S., L.R.C.P., RESIDENT MEDICAL OYFICER, BROMPTON HOSPITAL FOR DISEAEES OF THE CHEST; $\triangle N D$

T. HOLMES SFLLORS, M.A., B.M.Oxon., CaSUALTY SCRGiCAl OFFICER, MIDDLEEEX HOSPITAL; G. H. HUNT TRAVELLING SCHOLAR, UNIVERSITY OF OXFORD.

Pulmonary fibrosis in childhood inflicts such a physical handicap on its victims in later life that a short account of our attempts to investigate the origin and subsequent course of the disease may be of general interest and lead to further study. The materials for the investigation have been gathered from the records of the Brompton Hospital, and in the main confirm those recently published by $\mathrm{Dr}$. Burton Wood." We are using the term "pulmonary fibrosis" because it is at present the most familiar designation of the disease known as fibrosis, fibroid induration, chronic broncho-pneumonia, chronic basal pulmonary catarrh, and early bronchiectasis-which titles, we believe, indicate phases of the same condition.

Pulmonary fibrosis may be a disease entity per se, but it is commonly secondary to an attack of bronchopmeumonia, usually of the subacute variety, following some of the infectious fevers, especially measles and whoopingcough. Broncho-pneumonia invariably produces some degree of bronchiolar dilatation, and persistence of the inflammation promotes fibroid thickening of the bronchioles and air cells; moreover, the slight dilatation is in itself a cause of the cough which tends in vicious sequence to increase the weakness of the tubular walls. Pulmonary fibrosis begins in early childhood, a fact explained partly by the special liability at that age to infection by measles and whooping-cough, and partly by certain peculiarities in the anatorny of the lungs-namely, the relatively large calibre of the bronchi, the thickness of their epithelial lining, and the thick, but yielding, walls of the alveoli; these are embryonic and infantile distinctions which have disappeared in a healthy child by the fifth year.

Quite early in the investigation we found it essential to impose certain arbitrary limits to our search so as to keep it within reasonable bounds, and therefore made use of only such cases as fulfilled the following conditions:

(a) The age at the first examination must have been under 15 years.

(b) Each case selected must have been under observation for at least six months.

(c) Physical signs must have been present at the first examination and persisted over the whole period of attendance.

(d) At least five years must have elapsed since the last attendance.

Cases with any evidence of pulmonary tuberculosis or established bronchiectasis (at the first attendance) were excluded.

More than 23,000 notes from the out-patient department of the Brompton Hospital were reviewed, and 259 patients apparently suitable for investigation were followed up. Of these, 7 were found to have died and are not included in this report, but 53 attended and form the basis of inquiry.

At our examination a full clinical survey was made, with special reference to the following features: (a) Clinical history since last attendance at hospital. (b) Symptoms with particular reference to normal life and work. (c) Physique and capacity for work. (d) Physical signs in lungs.
Cissification.

The 53 cases are classified from an economic standpoint; we use the term "fit" to imply the capacity of an individual for a normal useful life.

1. Fit, without signs or symptoms-resolution has taken place in the interval

2. Fit, but with physical signs-permanent injury to lung tissue, but no apparent impairnent of general health

3. Not fit and with physical signs-permanent injury to lung tissue accompanied by some degree of constitutional disability ...

4. Bronchicetasis has supervened since last examined

\section{Comments.}

Complete Resolution.-This group is small but definite; tho notes show that no improvement had accrued during the period of treatment, and it is impossible to judge the ago at which the induration resolved.

lersistent Signs, but no Symptoms. - It is remarkable that a good physique and geweral health can be maintained in spite of permanent damage to lung tissue.

Persistent Fibrosis. - These a ases are the most numerous, and, with the next group, eonstitute a grave indictment of present treatment of the disease. The srmptoms and signs are compatible in most cases; there is an increased tendency to coughs and colds, and the majority are confined to bed or house at frequent intervals during the winter months.

Bronchiertasis.--As mentioned previousls, we rejected cases which showed the presence of established bronchiectasis while attending hospital, and this group only includes those in which the condition has developed since last seen. The number is small, but in addition the accomts of the seren deatins suggested this as the terminal cause.

syphilis.-None of the patients examined exhibited clinical evidence of svphilis.

Pulmonary Tuberculosis.-All patients were cxamined for tuberculosis, and oniy one was found to have tubercle bacilli in the sputum. This case is not included in our figures.

$$
\text { Cacisation. }
$$

The primary causes were:

\begin{tabular}{|c|c|c|c|}
\hline & & & Cases. \\
\hline Measles alone & ... & ... & $14(26.5 \%)$ \\
\hline Whooping-cough alone & ... & $\ldots$ & $8(15 \%)$ \\
\hline Measles with whooping-cough & $\ldots$ & $\ldots$ & $16(30 \%)$ \\
\hline "Pncumonia $" \quad \ldots \quad$... & $\ldots$ & & $14(26.5 \%)$ \\
\hline Scarlet Fever $\quad \ldots$ & $\ldots$ & $\ldots$ & $1(2 \%)$ \\
\hline
\end{tabular}

An accurate history of broncho-pneumonia following these ferers could not be definitely established, but was suggested in the majority of cases. Broncho-pnenmonia is a frequent and often fatal complication of measles, and among the poor or weakly is apt to run an irregular but persistent course. It may last as long as six weeks, or even more, and in such a case fibrosis will probably ensue. Bronchopneumonia is also the most serious complication of whooping-cough, and accounts for nine-tenths of the deaths from the disease. Our cases support the view that these two infections are mainly responsible for the production of pulmonary fibrosis. As the severity of both decreases with each year after the second, the fatalistic attitude of the laity - "let them catch it and get it over"-is to be deplored; since after the fifth year there is little danger of severe pulmonary complications to be feared from the infection or its sequel, every effort should be engaged to guard young children from any risk of contracting either, and especially should children with measles be protected from whooping-cough. "Pneumonia" appears frequently in the histories and gives rise to some confusion, for lobar inflammation is probably not intended; it is not a frequent complication of the fevers, and if present is always of a lobular variety. It would appear likely that a combination of impaired percussion note, weakened puerile breath sounds, and crepitations occurring in a febrile child might well at first sight suggest a diagnosis of lobar pneumonia, whereas actually the condition represents an exacerbation in a fibrotic lung. 


\section{Symptoms and Signs.}

The following symptoms and signs were found in patients who were unfit. Cough was invariably an early symptom, aggravated by cold and damp weather, and tending to become worse year by year; very marked liability to take cold was one of the most prominent features of the condition. If the cough became persistently paroxysmal a definite dilatation of the bronchioles was to be assumed: Slight breathlessness on exertion, and in advanced cases slight cyanosis, with parrot-bill clubbing of the fingers, pointed to right heart embarrassment. Contrary to the prevalent opinion, we found that the clubbing tended more to the early "parrot-bill" than the "drumstick" type. The sputum was scanty in quantity without characteristic peculiarity, unless bronchiectasis had intervened. The disease was almost always unilateral. The configuration of the thorax was often affected, there being slight scoliosis with narrowing of the interspaces and drooping of the shoulder; retraction to a degree indicating extensive pleural adhesion was not observed in any instance, nor was the heart markedly displaced. Respiratory movements and sounds were diminished over the diseased lung, and adventitious sounds were occasionally present. $X$-ray investigation following lipiodol injection into the bronchi would have been desirable, but was impracticable on account of the patients' daily routine; radiograms were taken in some cases.

Treatment.

Without entering closely into details we would like to point out that certain indications are clear, of which the need of more efficient prophylaxis is the most prominent. Broncho-pneumonia (whether so-called primary or secondary to measles and whooping-cough) is well known to be the cause of a large number of deaths in childhood, but it is not so generally recognized that as a persistent sequel of these infections it leads to the disability which is the subject of this investigation. Too much emphasis, therefore, cannot be laid on the after-care of cases of measles and whooping-cough. In the treatment of incomplete resolution attempts must be made to reventilate the sclerosed areas by means of breathing exercises; patients are now being treated in this manner at Brompton with very beneficial results, but it is as yet too early to speak of permanent benefit. In early cases reventilation and expansion of lung are desirable, but where bronchiolar dilatation has occurred and appears to be becoming permanent, natural or artificial methods of reducing the size of the thoracic cavity to allow for the ensuing cicatrization should be considered. If the child is roung enough the chest wall will probably retract sufficiently for some degree of compensation; but when the thorax is too rigid more radical measures-artificial pneumothorax, phrenicotomy, or more extensive surgical measures-may be indicated. Failing employment of such procedures, permanence of signs and symptoms may be expected, and treatment can only be symptomatic.

\section{Illustrative Cases.}

Grovp I.

A boy, aged $5 \frac{1}{2}$ years. Whooping-cough one year previously, since when he was never really well; persistent cough. Examination showed impaired percussion note, weak breath sounds, and crepitations at the right base. The patient attended for six months, at the end of which time the signs were still persisting.

Re-examined aged 21 . Has been very well for many years, and is able to do heavy work. All physical signs completely cleared up. A boy, aged 11. Measles two years previously, followed by "pneumonia," since when he had had constant cough and sputum Examination showed impaired note, weak breath sounds, and râles at right base. Diagnosed as fibrosis of lung. Signs did not clear up. Re-examined aged 23. Now perfectly well, working. Signs no longer present.

\section{Group II.}

A girl, aged $7 \frac{1}{2}$. Measles and whooping-cough three years previously, since when frequent cough. Examination showed rhonchi and crepitations at both bases. Attended for seven months; signs did not clear up.

Re-examined aged 22. Healthy-looking woman; feels well and is able to work. No cough or sputum. Impaired note, weak breath sounds, and post-tussive crepitations at right base.

A girl, aged $7 \frac{1}{2}$. Whooping-cough three years previously, since when persistent cough. Examination showed impaired note, weak breath sounds, and crepitations at right base. Diagnosis-? early bronchiectasis. Signs persisted during attendance.

Re-examined aged 23. Has been quite well for years. Able to work. Signs as before. No cough or sputum. Not subject to colds.

Group III

A girl, aged 5. Measles one year previously, since when cough and dyspnoea. Examination showed numerous crepitations at the left base, and these persisted during six months' attendance.

Re-examined aged 24. Pale, muddy complexion. Always has cough and about half an ounce daily of non-offensive sputum. Exacerbation of symptoms occurs every two to four months, necessitating retirement to bed. Able to work between attacks, but not completely fit.

A boy, aged $12 \frac{1}{2}$. Measles and whooping-cough two years previously, since when persistent cough. Examination showed weak breath sounds and coarse râles at the right base.

Re-examined aged 20. Always has cough with slight amount of sputum. Frequent colds, able to work, but not completely fit. Signs as before.

\section{Group IV.}

A boy, aged $8 \frac{1}{2}$. Measles followed by whooping-cough when 6 months old, since when persistent cough. Examination showed coarse râles at both bases. The child never coughed up any sputum, but the signs did not clear up.

Re-examined aged $13 \frac{1}{\frac{1}{2}}$. Typical bronchiectasis with offensive sputum, confirmed by $x$-ray examination.

A girl, aged 6. Whooping-cough one year previously, since when persistent cough. Examination showed numerous crepitations at the right base. Diagnosis-? bronchiectasis.

Re-examined aged 14. Typical bronchiectasis with offensive sputum.

Conclusions.

1. Pulmonary fibrosis of non-tuberculous origin frequently produces grave disability and seriously reduces the subject's economic efficiency; on the other hand, a reasonable proportion establish an "immunity" and labour under no apparent disadvantage.

2. Pulmonary fibrosis is a not infrequent consequence of the protracted form of broncho-pneumonia which follows measles and whooping-cough.

3. Protection against measles and whooping-cough in the first five rears of life would tend to prevent its incidence.

4. Apait from prophylaxis, amelioration, if not absolute cure, may be expected by improved methods of treatment.

It will be noted that we have used the term " pulmonary fibrosis" throughout as a label for the condition, but this is not altogether satisfactory, and there would appear to be a distinct need for an official discussion with a view to determining the nomenelature.

Our thanks are due to the honorary staff of the Brompton Hospital for permission to make use of their records, also to the lady almoners for their assistance in tracing cases. For suggestions and advice we are indebted to Drs. G. E. Beaumont and W. H. Lister.

RFFERENCE.

1 Lancet, March 24th, 1928.

\section{SOLITARY ULCER OF THE BLADDER. \\ BY} GUY CHAMBERS, F.R.C.S.ENG.,

HONORARY SURGEON, ISLE OF WIGHT COUNTY HOSPITAL; LATE CLINICAL ASSISTANT, ST. PETER'S HOSPITAL FOR STONE.

Ir is a matter of some interest that a review of the literature on general and urinary surgery reveals the fact that this condition is enshrouded in a certain degree of obscurity. In some works the disease fails to be identified as a clinical entity from other varieties of chronic ulceration, in others it is not even mentioned. Certain well-known writers, on the other hand, give the subject considerable attention and description under titles which appear to be synonymous.

Rowlands and Turner (1927) describe the chronic or callows ulcer of the bladder, which occurs nearly always in young men, but occasionally in women who have borne children. Haematuria is a fairly constant symptom. The condition was mentioned by Fenwick in $1900,{ }^{1}$ and again in 1904.2 V. C. Hunt ${ }^{3}$ discourses on submucous ulcers of the bladder, advises their excision, and the treatment of septic foci affecting the tonsils, teeth, nasal sinuses, etc.

Cabot describes a solitary ulcer that may be either acute or chronic. He mentions also an elusive ulcer that occurs chiefly in females and is associated with great frequency of micturition but without haematuria. 